\title{
J
}

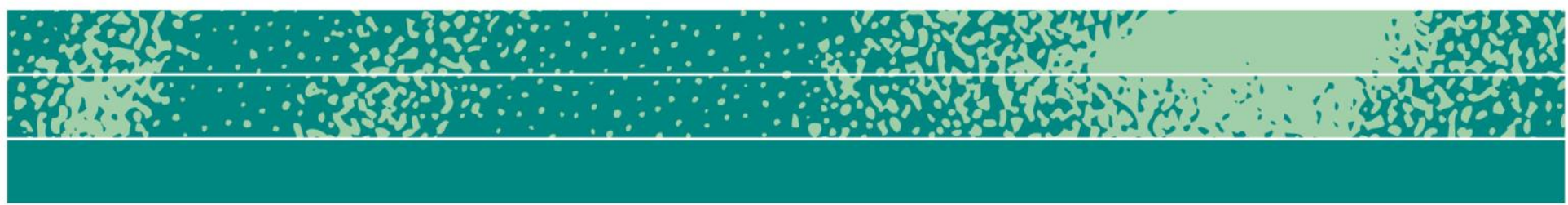

\section{Inside the Energy Salon: Installation and Illusions of Finality}

Arthur Mason

\begin{abstract}
This article analyzes promotional images associated with energy events as ethnographic objects in their own right. I examine how the sensory experience of promotional imagery with its fantasy display contributes to the rational presentation of energy planning, with its emphasis on accountability through expert knowledge provisioning. Promotional images fall under the rubric of impression management where an ideal of believability mediates between objects of manufacture and their desire. Informed by the works of artists Marcel Duchamp and Andy Warhol, I frame these images as an illusion of finality, which I then connect to a broader argument about the rise of an energy salon-a shift that appears to involve an increased prominence of visual attention and management in how energy expertise is produced, performed, and circulated.
\end{abstract}

Page 1 of 18

\section{Keywords}

Energy planning, expertise, impression management, restructured industries, promotional cultures 
In April 2013 I attended the Arctic Summit energy roundtable event at the upscale Hotel Bristol in Oslo, sponsored by an Events Group for the British weekly magazine The Economist. ${ }^{1}$ The full title of the gathering was Arctic Summit: A new vista for trade, energy, and environment. Its focus was the future of Arctic oil and natural gas development. Handouts for participants included glossy event pamphlets with elaborate graphic design imagery. Take, for example, the Arctic Summit delegate booklet, ${ }^{2}$ whose subtitle poses the question: What will the Arctic resemble in 2050?

Printed on the cover is an attention-grabbing visual: the background scene is a graphic-design illusion of a dark blue sky and sea that is cut horizontally across the middle by a strip of snow-covered mountains. This artificial backdrop intensifies the realism of a foregrounded photographic image depicting an ice-covered rocky island. At the island's base, the viewer witnesses an illusion that logically corresponds to the island's mirrored reflection upon the sea. Yet through computer design wizardry, the reflection is not the mirrored image of the island, but instead, the details of an upside down industrial offshore oil rig (see Figure 1).

Thus, in response to the question emblazoned on the book cover, What will the Arctic resemble in 2050?, the visual responds with a fantasy illusion of a climate changed ice-free Arctic Ocean and an uninhabited island whose mirrored reflection is a multi-million dollar offshore installation. By placing the visual alongside the event slogan, this fantasy illusion is immediately recognizable as the projected possibility of the Arctic future in the year 2050. It is not an illusion of the Arctic in the year 2040, or even 2049 and three-months, but an illusion of a singular temporality by alignment with its slogan identity. Importantly, the image does not carry the weight of accountability associated with an expert scenario projection. Its fantasy proposition is evidenced by the absence of any credible authorship outside its ownership by The Economist Events Group.

\footnotetext{
${ }^{1}$ Funding for this research comes from the Norwegian-US Fulbright Foundation (2013) and the US National Science Foundation (2010-2017). I thank Traci Speed, Brian Moeran, and two anonymous reviewers for their instructive comments.

2 The booklet was also available online in downloadable PDF format. A second handout was an industry report titled Arctic Update from DNV to the Maritime, Oil and Gas Industries, and it, too, was available in PDF format. The latter report was published by one of Norway's largest strategic knowledge firms, Det Norske Veritas (DNV), a sponsor of the event. Finally, a third booklet, titled The British Ambassador's Residence in Oslo, was available for participants who attended the cocktail and networking reception scheduled to take place at the forenamed location. This booklet did not appear online as a downloadable document, but details were available in web format.
} 


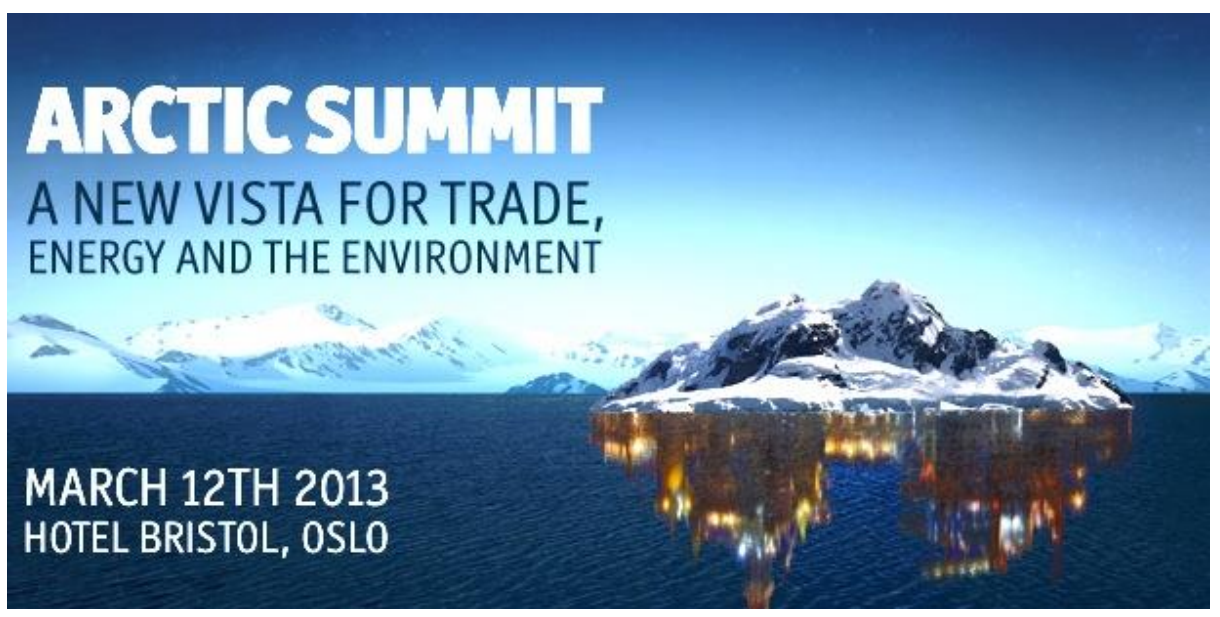

Figure 1: Arctic Summit Image

In this article, I present this promotional image as a key visual at an energy roundtable event. I describe its aesthetic treatment and placement next to people and things. My objective is to take promotional images associated with energy events as ethnographic objects in their own right. I want to know how the sensory experience of promotional imagery, centered on fantasy display, contributes to the rational presentation of energy planning, with its emphasis on accountability through expert knowledge provisioning. Promotional images fall under the rubric of impression management (Moeran 2005) or what Lucien Karpik (2010:44) calls "judgment devices"-suggesting that an ideal of trust or believability can mediate between objects of manufacture and their desire. In consumer packaging, for example, promotional imagery aims to generate values associated with the identity of objects, even while acknowledging the contingency of this aim (Wernick 1994). In the context of energy planning, where foresight knowledge is characterized by uncertainty, promotional images may assist in the exercise of judgment. Energy futures are detailed expectations that represent strategic resources for attracting attention from (financial) sponsors to stimulate agenda-setting processes. They are also commodities whose value is only indirectly based on their cost of purchase. As such, valuing the uniqueness of products such as energy forecasts requires forms of judgment that can assist in identifying quality beyond attention to economic price, or as Karpik states, "when actors give more weight to qualities than to price...choice takes the form of judgment (Ibid: 39, emphasis in text).

I consider energy promotional images as a type of artefactual data, whose other types include expert reports, graphs, and scenario narratives. Artefactual data are material- and digital-forms of knowledge representing "integrated packages" that capture an advisory firm or event group's activity of transforming information into knowledge purporting to have strategic decision-making value (Knox et al 2007:22). Unlike with other types of artefactual data, however, I face a substantial challenge here since, despite their ubiquity, at no time during energy events are the 
meanings of promotional images discussed. Thus, I turn to an analysis informed by the works of artists Marcel Duchamp and Andy Warhol to frame these images as an illusion of finality, which I then connect to my broader argument about the rise of an energy salon-a shift that appears to involve an increased prominence of visual attention and management in how energy expertise is produced, performed, and circulated.

Energy roundtable meetings like the Arctic Summit are key networking events that attract the attention of government officials, company executives, academics, and journalists who seek consensus about the future of energy markets. They are ritualized learning environments, organized by event groups and advisory firms, which create interpretation around imagined energy futures. Because of their emphasis on communication through display, energy events share similar features with a type of ritual eventing that anthropologists associate with "tournament" economies-book fairs, fashion weeks, or award ceremonies-in which participants compete for prestige through selfpresentation (Moeran 2010: 133-140; Appadurai 1986). The visibility of rank at such tournaments, for example, may be equated with the performance of consultants at energy events, in the sense that the linguistic repertoire of technical terms, acronyms, and nonverbal signs such as hand gestures (Agha 2007; Silverstein 2006) are consequential for the display of mastery over energy futures. Also, tournaments enroll periodicity as an instrument for distancing the routines of everyday economic life. Similarly, energy events rely on spatio-temporal features such as the division of the given time into, on the one hand, plenary sessions that everyone can attend and, on the other, parallel sessions that participants must choose among. Such allocation of individual and collective discussion through conferencing can provide "exemplary instances and instruments of future-management" (Wallace 2010: chapter 3).

Conceptually, tournaments of values place emphasis on the position-taking of competitors who act within a social field with the aim of accumulating prestige value. In what might be the earliest example of impression management documented by an anthropologist, Bronislaw Malinowski (1984: 62) notes the significance of quantifiable matter among Trobriand Islanders: "After they are harvested, yams are displayed for some time piled up in neat, conical heaps [exhibited for aesthetic polish, arrangement, criticism, admiration, comparison and praise]". Here, the appearance of quantification becomes a force for the extension and circulation of a person through his name, which reverberates in the minds and speech of others, what Nancy Munn (1986) calls "Fame". In the present context, I am less interested in what is performed at energy events than in what is shared through establishing a community of interpretation (Mason 2007:374). By this, I refer to the way in which energy events associate new relationships among attendants, a process requiring social authority, intellectual technology, and practical activity, 
not unlike what Timothy Malefyt (2003) refers to as the work-shopping of consensus by advertising firms.

For analytical purposes then, I consider energy events as analogous to a modern day aristocratic salon. Norbert Elias (2006) explains that in the eighteenth century salon participants increased their knowledge and refined their taste through conversation. In salon culture, etiquette, spatial relations, and modes of visualization are objects of representation which structure the image that aristocrats have of themselves (Delacour and Leca 2011:37). In a similar manner, the modern day energy roundtable is a type of elite experience that emphasizes luxury, etiquette, and security-producing a lifestyle that reinforces the veracity of strategic knowledge associated with energy planning. Such events take place in four-star hotels in major cities across the globe. Every detail is elaborately staged for each occasion, including personal name placards, menus, table settings, brochures, and the like. While the notion of tournament economy places emphasis on the consecration of individuality through the extension of one's fame (Munn 1986), energy salon culture aims toward glamorizing practices of interpretation with the aim of cultivating alignment through a celebrated aesthetic. That is, while the collective form of the tournament economy embraces a "carnivalistic logic" (Bakhtin 1994, chapter 4) structured on the principle of contestation (Moeran and Pedersen 2011:5), energy salon culture leans toward religious ceremony in which ritualized meaning is subordinate to structure.

To orient the reader to the stakes of my research, I first introduce the conditions that establish the possibility for an energy salon and then characterize promotional images, connecting their analysis with my broader assertion about an energy salon more explicitly. The key role that promotional images play in the rise of the energy salon is tightly wound around the idea that such images produce an illusion of finality. That is, promotional images are objects that aim toward the specific end of producing a finality that exists as part of an effort by an expertise regime to transcend its ideological conditions of origin. As such, promotional images produce a delicate ubiquitous image that is post-discursive and, in some sense, post-contextual (Žižek 1991). In this sense, such images serve as a type of "judgment device" capable of contributing to the active weighing of knowledge from trusted sources (Karpik 2010:44-45).

\section{Rise of the energy salon}

Energy events today are costly to attend, with heightened security to ensure that only those persons legitimately in attendance gain access to knowledge. Both the types of locations where events take place and the actors who appear contribute to their sanctioning-as, for example, when Secretary of State Hillary Clinton addressed Cambridge Energy Week 2010 at the newly built Hilton Hotel in Houston. Elsewhere I attribute the 
rise of these events to changes beginning in the 1970s in arenas associated with energy restructuring, environmental perception, and communication technology that provide opportunities for various types of advisory experts-mainly economists-to assemble, package, and perform knowledge about energy provisioning in new ways that can elevate the interests of industry and government into actionable views (Mason 2006, 2007). Such changes include the reorganization of information related to energy systems development: for example, coal, no longer intimately associated with labor politics, is now seen instead as a fuel, alongside oil and natural gas, in a context of electric power generation.

Such shifts coincide with what I call the disembedding of a culture of expertise during the 1980s and, specifically, with changes in preferences for representing knowledge visually from text to graphic design. What many refer to as the Reagan era of "defunding the left", for example, I see as a shift to the private sector of a first generation of government risk assessors, initially trained in response to a regulatory need for technical evaluation in the wake of the 1970s Congressional environmental legislations. As this relates to imagery, juridical representation of knowledge through text begins to appear backwardlooking, especially when compared to the imagery employed by economists, whose graphic projections are forward-looking.

Also taking place at this time is the increasing relevance of economic knowledge in the service of government-as evidenced through the application of cost-benefit analysis in decision-making, particularly in environmental regulation, suggesting a shift from juridical evaluation to favoring economic efficiency through mathematical modelling. The introduction of this shift, what was to be called reform, was especially welcomed in the arenas of energy production where industry sought to leaven the "dead hand of regulation", as the perceived cause of the 1970s energy supply crisis was already being referred to by policy analysts of the time (Wilson 1971). Thus disembedding, as I employ the term, refers to the (neoliberal) marketing of scientific evaluation among persons whose expertise remained indispensable to satisfying the requirements associated with regulation.

During this same period, environmental activist organizations came to rely on scientific representations of truth to generate an empathy for the planet. As such, the authenticity of their message begins to rely less on the drama of personal risk-taking. This is especially so among organizations which acquire media enterprises, and which therefore no longer have to depend upon an independent news estate to stage the verification of their truths. As evidence, consider the shift in activist organizations that during the 1990s sought to alter the dynamics of collective life by fostering an ecological sensibility by reference to media stunts (Wapner 1995). Today, converting mass audiences toward 
planetary concern often requires employing images that stress an empathy for the graph, such as those prominently on display in the movie Inconvenient Truth.

Other efforts aimed at assembling knowledge include, for example, the establishment of government houses directed toward collecting reliable data from ever wider aspects of energy arenas-in part by imposing mandatory accounting on firms and creating a rationalized reporting system, as happened in the wake of the OPEC embargo. The institutionalization of energy knowledge provisioning through the US Energy Information Agency provides a new opportunity for independent experts to repackage otherwise hard-to-find data.

What I see in the above narrative is differentiation between, on the one hand, economic experts who transcend proprietary limitations and, on the other hand, legal expertise which remains tethered to attorneyclient privilege and which is thus incapable of advocating an industrywide horizon of expectation. The use of visuals (graphs) to frame the economic future as accessible in one glance intensifies this differentiation. As such, within the energy system, legal knowledge is increasingly backended, represented by "partial intellectuals" (Bauman 1987:114) whom industry and government rely on to deliver historical precedent. By contrast, economic knowledge emerges as vanguard, that is, capable of making claims in the form of statements intended not for clients, but on behalf of impersonal forces (the market, the future). From this, epistemic interests appear distanced from proprietary claims, lending to knowledge a prestige value whose independent stance appears as a natural attribute.

It is within this context that a newly established role for the executive round table event emerges. Identifying knowledge with a neutral value creates the possibility for inviting competing parties to gather around individual announcements in a shared setting. Where competing parties can stage their individual market condition without threat to their individual proprietary position, the experience is visual, independent, sequestered, and shared. Nevertheless, the quality of this new type of expression, what I call the energy salon, represents reliability where the conditions of veracity are abstracted from any actually existing assembly of data, and as such, are dependent upon the eventing itself.

Inside the energy salon, aesthetic exposure is a prerequisite for ensuring reliability. Within, the energy salon offers an opportunity to witness an expanded typology of delicate experiences that serve as a trademark for the veracity of expert knowledge, including attention to the spatial arrangement of security. At energy events, the proximity to knowledge aligns with a movement from ostentatious forms of enforcement toward more delicate forms of identification. At the street entrance to events, for example, the bodies of security guards are conspicuously robust, whereas the corporeality of attendants who deliver booklets to clients appears thin and feminine. This materiality of security 
entails its own redundancy in the distancing of delicacy, where metal turnstiles located at the entrance of buildings give way to barcode scanning inside conference rooms. The cost for event attendance is stratospheric ( $\$ 15,000$ for three days at the Oslo Energy Forum), suggesting that price, in combination with security and luxury, contributes to the delicacy of semantic provisioning.

Also, there is a commitment to an aesthetic of abstraction that displaces conspicuous recognition with artistic impression. At the Hotel Bristol, the meeting place for the Arctic Summit, an oil painting depicting naked boys frolicking at the seaside meets an ambivalent gaze from participants suggesting that inside the energy salon, erotic imagery is an abstract theme; in this case, the traffic in pedophilic desire could well be an image signifying an age of innocence. ${ }^{3}$ Similarly, in what appears as a concerted appeal to cubism, oil paintings hanging on the mezzanine floor en route to an energy roundtable inside the Corinthia Hotel, St.

Petersburg, seemingly collude with the event's Power Point images depicting petro-geologic futures. What presumably began as a way to ensure reliability of knowledge in energy decision-making is today inside the energy salon a way to ensure sociality through a lifestyle of semantic provisioning, whereby energy policy knowledge is established through an aesthetics whose reliability is a preference for delicacy.

\section{Manufactuality: an object of manufacture and factuality}

An energy event key promotional image is an artfully designed computer graphic visual that appears on brochures, event booklets, and banners. It thematically channels the assembly of energy facts into one dramatic and immediately recognizable visual. It is replicated in various sizes and locations, appearing on event banners, wall-sized backdrops, internet pages, booklets, writing-pads, and PowerPoint slides. The key image possesses strong qualitative aspects such as those images that typify realistic renderings, for example, classical art. As such, the shapes and colors that weight the key image with its dramaturgical form strike a marked contrast with the barely identifiable meanings of the linear and bar graphs used by the energy experts who are the key presenters at these events. Finally, an event-date and slogan is typically printed directly onto the key image, conveying duration (one to three days) and central theme. Examples of slogans include: The new face of risk, and What will the Arctic resemble in 2050?

While average exposure to a key promotional image results in sightings by participants that can be counted in the hundreds, I have

\footnotetext{
${ }^{3}$ I thank Norwegian anthropologist Kari Storaas for inspiring this observation and for alerting me to the cultural significance of the "Moorish Hall," as the lobby of Oslo's Bristol Hotel is referred to, originally conceived as a gallery for artistic display before its high ceiling was lowered in order to create a mezzanine floor for conferencing space to host events such as the Arctic Summit.
} 
never overheard an event participant refer to a promotional image. I have accepted this absence of discussion as evidence that such images are perceived as superfluous and that the images affect a type of namebranding practice (logoization of pens, stationary, brochures) that is common among the upscale hotels in which these roundtable events take place. Furthermore, the necessity of promotional imagery does not appear to me to be as critical as other auxiliary features: for example, the energy and security requirements of roundtable events where, in the case of the former, reliable electricity flow ensures internet capability, and in the latter, elaborate forms of security (guards, turnstiles, ID badges) guide the etiquette of interpersonal interaction (Mason 2012). Security may also be seen as an ostentatious marking of boundaries between insiders and outsiders especially for highlighting one's competence through lifestyle provisioning or extravagance (Havens 2011:155).

Nevertheless, attention to these promotional images suggests that they do possess design and installation features that differentiate them from the other types of images on display. Unlike, for example, the hotel logo used to indicate an enterprise identity, the event key image is almost always marked in ways that give its appearance a ritualistic function. The event date that is printed onto the promotional image stresses the eventness or unique time dimension of the gathering. Furthermore, the datestamp attributes the key image with an obligatory obsolescence (once the event has passed), and in this way confers upon it a non-transferable identity.

Moreover, the presence of two contrasting types of visuals-promotional images that appear real (but are fabricated) and energy planning images that look abstract (yet are authentic to reality)-expresses a peculiar juxtaposition taking place within the same restricted time-space of social interaction. On the one hand, key promotional images, designed by artists, apply techniques of scale and aesthetics that do not associate the visuals with forms of accountability aimed at legitimizing an actual reality. On the other hand, expert energy graphics suggest forms of reliability whereby authenticity is scrutinized prior to circulation. That is, the kinds of assessments that experts make available through PowerPoint images, while not subject to the strict controls of independent scientific knowledge (Shapin 1994), do have their own particular forms of accountability (McKenna 2006). Thus, while promotional imagery does not require the accountability employed in the graphs of advisory expertise, both types of visuals (along with decisions regarding how they are assembled and where they circulate) are aimed at the same target groups.

These differences in aesthetic positioning-the presence versus absence of repetition; realism through fabrication versus authenticity through abstraction; the lack of discussion versus intense interpretation-suggest that what is being promoted through promotional 
imagery is a mixture of both manufacture and factuality (what I refer to as manufuactuality) aimed at absorbing the complexity of energy expertise into an illusion of finality. That is, a key promotional image at energy events presents an illusion that assigns a finality of form to the content of any and all discussion, in spite of what individual meanings of accountability and authenticity remain.

My inspiration for manufactuality derives from an article appearing in The New Yorker magazine several years ago by art historian Louis Menand (2010), who offered a few reminders about the critical reception of mid-twentieth century modern art. In discussing Pop artist Andy Warhol, Menand first introduced art historian Betran Rouge's comparison of Warhol to the artist Marcel Duchamp. Among Duchamp's innovations was placing everyday manufactured objects in an art gallery. By their very positioning within a gallery space, the identity of these everyday objects was transformed into an artwork. Duchamp referred to this process as the ready-made. The ready-made, on the basis of installation, rejects the logic of a final identity that is assigned to consumer objects. That is, by the assignment of meaning through its installation in various settings, Duchamp pointed out that the identity of an industrial object was flexible and that its function could be reassigned through performance. For example, inside the gallery-space the ready-made carries the identity of art, while inside the kitchen-space the ready-made is an appliance. Thus, the ready-made draws attention to the identity conferred by installation.

According to Menand, Rouge argued that Warhol's innovation was to create an imitation of the Duchamp ready-made. Through artistic recreation of an everyday object-for example, Brillo boxes as artefacts of artistic production-Warhol replicated what industry had already fabricated as a final object. In this way, Warhol created an illusion of a consumer-object-of-finality (in abbreviated terms, an illusion of finality). Set within the context of historical development, if you will, an object's everyday finality, which Duchamp transformed into flexibility by installation, was in the hands of Warhol transformed back into finality by way of its replication through illusion.

At this point in the discussion, I want to add two suggestions. First, as evidenced by the emphasis he placed on consumer packaging (that is, in contrast to Menand and Rouge's argument), Warhol was not that interested in the identity of manufactured objects as much as he was fascinated by their representation through the graphic design visual. Second, Menand reminds his readers that Warhol's work was usually sold piecemeal to collectors, and that it is easy to forget that virtually all of his art exhibitions were installations. That is, by creating replications of consumer packaging and then arranging them in an installation, Warhol transformed the reality of the art gallery into a make-believe supermarket. And here is where Menand ends his thesis-with the disappointing summary that "art is a commodity." What Menand does not 
grasp, however, is that by mimicking the reality of the supermarket inside an art-gallery, Warhol demonstrated how the reality of the supermarket operates as a make-believe art-gallery.

Without embracing judgment on its ultimate purpose, as for example a kind of aesthetics regime for the molding of sensuality (Haug 1986), the supermarket-gallery is indeed an art-display, populated by consumer packaging that is produced by real artistic-craft persons whose accomplishments can be measured through their graduate degrees in art design. When you consider all the artistic packaging encountered by a consumer while walking down a supermarket aisle, which is nothing if not an art display-one, moreover, available to consumers at a fraction of the cost of gallery prints-what Warhol appears to have argued is that the supermarket-gallery was consciously being mistaken as mere advertisement, as if the content inside the packaging was of any real significance (Žižek 1991). Warhol's emphasis on visual design packaging suggests that consumer objects derive a final identity not from their manufacture and subsequent installation, but from the illusion of finality conferred through visual design and the subsequent installation of visual design in an artistic display.

On this same basis, in what follows I analyze a graphic design visual whose statement of purpose is to advertise the content of energy policy discussion. My argument is that the energy promotional visual is a key image whose redundancy of placement provides an illusion of finality that endorses the content of energy planning knowledge with its veracity. Much like the consumer packaging reproduced by Andy Warhol, key event images are themselves an illusion of finality by their singularity of uniqueness (the artist's creation) whose installation is in fact not superfluous, but instead assigns the content of any and all discussion through its finality of form.

\section{Arctic Summit: installation and illusion of finality}

Returning to the delegate booklet titled Arctic Summit: What will the Arctic resemble in 2050?, the visual for its cover was available in at least four unique formats at the Arctic Summit roundtable event. Each format reflects a specific physical location, size, and symbolic function.

First, the delegate booklet cover image appeared as a wall-sized banner hanging directly behind the central speaker stage. A row of ceiling floodlights shining onto the stage bathed the banner image with bright light. At 9-feet high and 20-feet wide, the banner backdrop image remained visible to participants throughout the day as a focal point of the event. Its size, the largest visual at the event, enveloped keynote speakers standing at a podium and various roundtable discussants seated across the stage. The banner backdrop image was broadcast onto two large overhead screens hanging down in the middle of the assembly room in 
order to project the stage activities to participants sitting in the back. When members of the audience rose from their seats to pose questions, a camera projected an image of participants directly onto the banner visual, so that the entire assembly's attention was always directed toward the stage, and thus toward the banner image. In this way, the delegate book's cover image became the event's key image: that is, always associated, potentially or actually, with each public speaking participant. Hence the key image formed a uniquely finalized visual space for containing public discussion. It divided all discourse into public and private. If participants did not appear projected onto the banner image, their speech was not part of public debate.

Sitting at the front of the stage and glancing across the room, I could identify a second format by the various ways participants interacted with the book cover image. For example, by the way participants placed the booklets on the white-clothed tables, just in front of them, near their drinks which stood nearby on coasters, I could see that the event key image had become integrated into a metaphorical structure of formal dining manners, appearing as a tablemat in a formal dining room experience. From its association with repeated displays of delicacy, such as the self-imposed demands of placing glasses on coasters and coffee cups on the doilies of saucers, the key image had become part of a delicate experience. By delicacy, I refer, for example, to the way participants held the booklet in their hands in such a manner that the event key image became integrated with associations related to hygiene, cleanliness, and proximity to shirt cuffs-that is, characteristics of personal touch familiar to such items as smartphones, keys, or wallets. ${ }^{4}$ In this way, the event's key image entered the structured intimacy of formalized elite etiquette. Its presence invited specific performances by participants who willingly conformed to the delicacies of its commands.

A third format emerged during the evening, when event participants were shuttled by tour bus to a networking event and cocktail reception at the British Ambassador's residence, the Villa Frognæs. Attendees had the opportunity to mingle with Jane Owen, British Ambassador to Norway, who also gave a welcoming speech to event participants. The Villa Frognæs is a mid-nineteenth century mansion whose interior rooms are adorned with paintings that typify scenes of delicately rendered landscapes in the style of Romanticism. On the second floor, at the main hallway entrance, participants were ushered past a sixfoot high and two-foot wide promotional banner carrying the event key image with the words "Networking Reception" emblazoned at the top of the banner. Another statement, "British Ambassador's Residence on 19th March," was printed at the bottom of the banner, just below the mirrored

\footnotetext{
${ }^{4}$ The widespread sense of delicacy that the energy industry places on touch is evidenced in such far-removed locations ranging from energy roundtables to the Schlumberger factory floor's injury prevention program, where ubiquitous slogans on posters announce, "fingers are very precious."
} 
image of the offshore installation in the area of the blue sea. Beneath this statement, a string of letters provided the website address for the Arctic Summit. Standing directly next to the banner image were two ornately decorated pieces of furniture, a delicate-looking dining chair and a dressing table. Above the dresser, and in visual alignment with the key event image, hung a landscape painting featuring various domesticated birds. In a similar manner of design, the colors of both the banner image and the landscape painting were dark along the outer portions and bright in the middle, lending the impression of a diptych effect to the two landscape images (separated in time by two centuries). Thus, The Economist's event key image and the Ambassador's Residence furnishings entered into a visual ensemble, as an installation of the sensible, whose immediacy of recognition aligned the projected fantasy of the Arctic in the year 2050 with a historic fantasy of artistic landscapes of Romantic paintings during the 1850 s.

Finally, the key image appeared on the event's section page of The Economist's website. The event key image could thereby be reproduced by participants through screen shots, or revisited through bookmarks, for examination in greater detail. It was located alongside links to particular organizational aspects falling under the titles: Overview, Agenda, Speakers, Gala Dinner, Sponsors, Supporters, Venue, Presentations. In this way, the event's key image, by its proximity to various event categories, became linked to these details, not only electronically but also symbolically, as a discursive form.

At no time were the meanings of the key image discussed. Authorship of the image is not referred to inside the delegate booklet or on the website. The repeated image of an Arctic island with a mirage of internal infrastructure is, therefore, left open to anyone's interpretation. Yet, from its fantastic quality-an island whose core is refashioned in technological form-one possible framing of the image is by reference to narratives that translate islands into inland-empires of technological wonder. An inland empire of technological wonder relies on the expertise of scientists and technocrats who do not seem to be affiliated with a university or any observable network of knowledge. Everything appears to be operating along lines of innovation that are self-enclosed and selfsufficient.

One of the more notable examples of this fiction is the depiction of Crab Key Island in the James Bond movie Doctor No. In the midst of a tropical paradise, Dr. Julius No, adversary of British intelligence officer James Bond, has installed an ultra-modern facility in the core of Crab Key. The internal island complex suggests many types of workers-architects at the design phase, engineers who ensure facility operation at maximum specification, and less skilled workers who carry out mundane functions requiring sober attitudes. Recent fictional portrayals of madmen translating islands into inland empires include Dr. Topenkof in the Jude 
Law and Gwyneth Paltrow movie Sky Captain and the World of Tomorrow, and the video game Skies of Deception, in which commander Diego Navarro creates the Archelon Fortress inside Terminus Island, accessible via Cobalt Cave (see also Mr. Roarke of the television series Fantasy Island). Eighteenth through twentieth-century novels such as Robinson Crusoe and The Island of Dr. Moreau offer prototype forms that favor translating an island's natural environment into a mask of superior techno-scientific operation (see also depictions of Easter Island and Skull Island). The characteristics common to each of these narratives include hidden techno-scientific infrastructure, secret charts, sequestered knowledge workers, unconstrained unreason, ocean-sized moats, and local inhabitants kept in the dark about their fate. Taken together, these stories make up a category of translation that I refer to as "islands of inland-empire."

A typology of real and imagined Arctic islands of inland empire include Iceland, whose outer shell is seemingly just a backdrop for the appearance of different shaped pipes crisscrossing the surface as physical manifestation of hidden geothermic wonders internal to its core. My first glimpse of such an island of inland empire occurred while flying over Kodiak Island, Alaska. There, beneath my plane, I saw Terror Lake, a dam built directly at the center of the island to provide hydropower to inhabitants of the fishing villages that dot the island's shoreline. When I saw Terror Lake, I realized something was going on behind my back: a vast techno-scientific plot-an economic schema that afforded me the biocapacity for writing about the culture of my informants. In Russia, a promotional installation at the St. Petersburg Economic Forum displays the Teriberka Natural Gas installation in miniature. It is a future technoscientific off-loading facility for developing the Shtokman energy project. Teriberka is located along the Barents Sea where today villagers live amidst modern day ruins. They also live in expectation that the Shtokman project will bring a new modernity. During a Norwegian Research Council-sponsored energy development event I had the opportunity to picnic in Teriberka where, amidst welcoming comments by mayor Valeri Yarantsev, the town appeared tragic and poetic, like the Hollywood movie set of Shutter Island with megastar Leonardo DiCaprio. Back in St. Petersburg, the promotional representation of Teriberka provides a visual example of its future in miniature, equipped with tiny workers of an Arctic island of inland empire.

From an industry-sponsored perspective, the image of an oil and gas rig in the shadow of an island may indeed suggest that the Arctic will soon be translated into an accessible and valuable hydrocarbon landscape. This is in fact the message of Henrik Madsen, CEO of the industrial concern DNV, and a keynote presenter and co-sponsor of the Arctic Summit event. Standing at the podium, with the event key image draped behind him, Madsen detailed a wide-ranging typology for requirements of Arctic offshore oil and gas development. Throughout 
Madsen's techno-scientific presentation, the event's key image remained behind him as a stable, silent, and legible visual of the projected Arctic future. Madsen himself, though not having publicly stated his approval of the key image, expressed his alignment by his willingness to stand before it while outlining future development (imagine, for example, the unreality of the same CEO making these statements while standing in front of a Nazi swastika banner). Thus, in the same manner in which proximity associates the key image with fixed temporality, formal etiquette, discursive space, artistic appreciation, and individual inspection, the image-through its acceptability as a background representation for a cosponsoring organization-is enrolled as a suitable proxy for numerous details concerning a wide-ranging typology for Arctic offshore oil and gas development. Twenty-five speakers in all took to the stage, offering contrasting viewpoints in as much detail as offered by Madsen. The event key image, therefore, whatever its meaning, was supportive of all perspectives of the speakers and roundtable discussants. In this way, the key event image was a silent public visual that was taken for granted by participants, instead of being openly debated for what it really was: an artificial vision whose finality of form absorbed representations of accountability and authenticity.

\section{Conclusion}

The energy salon is an object that I created for producing academic knowledge in the form of ethnographic typologies associated with energy planning. In this, I follow standard practice in anthropology of requiring a stable subject to create purposeful data-culture being the most notable of these methodological fictions. By constructing the salon-space, I draw attention to a common structure surrounding expert performance in which incidental characters (security, promotional images, etiquette) allow energy knowledge to form a center so as to appear agentive, singular, and authoritative. Returning to the work of Malinowski (1986), such incidental features function to give structure to otherwise uncertain and unpredictable circumstances. Malinowski's observations, for instance, describe the role of magical activity in giving a meaningful structure to the uncertainties of dangerous outer-lagoon fishing, which he contrasts with the relative absence of ritual and magic in the safer innerlagoon fishing. This work served as the classical anthropological illustration that ritual-like incidentals function to give a sense of predictability to contexts of insecurity. In other words, given the absence of a pragmatic means/end relationship, what Max Weber (1946) defined as reason and rationality under conditions of modernity (p. 152), the magical system provides capacity for reconciling "gigantic variations on the theme of the principle of Causality" (Levi-Strauss 1968: 11).

In the present case, my focus on promotional imagery suggests two features. First, the energy event key image is the accretion of a new 
material-epistemic investment, suggesting a historical development in the management and stabilization of interpretation in energy planning. That is, where qualitative knowledge of energy futures is highly unpredictable, the piling up of so-called judgment devices, in this case promotional imagery, works to shore up the legitimacy of expert predictions. Promotional imagery therefore is an auxiliary instrument as part of this investment. At energy roundtable events, the promotional image suggests the unanimous embrace of a key visual whose individual meanings are displaced by its ritualized enrollment as a proxy for a fixed temporality, formalized etiquette, discursive space, artistic installation, and individual identification. Its presence inside the energy salon contributes to the transformation of all things and experiences toward the economic accumulations and risks that surround energy planning. Through installation and illusion, promotional images at roundtable events intensify the distribution across varied spatial and personal recesses of a shared judgment about the salon-an idea about the integrity of knowledge whose strengths might otherwise have to be weighted solely on dramaturgical centralized locations such as the speaking subject of expertise.

Second, the promotional image achieves its own singularity of visual form by its installation in the contrasting authenticity of expert images, and thus forms its own center. In this way, the key promotional image contributes toward an emerging epic structure of the Energy Salon itself, where the incidental character of the key image finds the particular pedestal of its unique form in the ubiquity, immediacy of recognition, and silence of distribution across varied spatial and personal recesses. Film critic Vlada Petric (1999) considers a similar task in his discussion of epic structure in the film Andrei Rublev, Andrei Tarkovsky's film depicting the life of a medieval religious painter. In one passage, Petric points out that one of the essential features of epic structure in literature, movies, or painting is that each character forms a center: "If you concentrate on any one figure of [Vittore] Carpaccio's paintings you begin to see with unmistakable clarity that everything else is mere context, background, built up as a kind of pedestal for this incidental character. Likewise, in almost of every episode of Andrei Rublev there is an incidental character raised to the pedestal with the protagonist acting almost as an incidental character".

Likewise, the event key image builds on existing practice of stabilizing uncertain energy futures through its self-enclosed ideological form which remains both an incidental characteristic and ubiquitous figure of the energy salon. 


\section{References}

Agha, A. 2007. Language and Social Relations. New York: Cambridge University Press.

Appadurai, A. (ed.) 1986. The Social Life of Things. Cambridge: University of Cambridge Press.

Bakhtin, M. 1994. Discourse in the Novel. In M. Holquist (ed.) The Dialogical Imagination. Austin: University of Texas Press.

Bauman, Z. 1987. Legislators and Interpreters. Ithaca: Cornell University Press.

Delacour H. and B. Leca. 2011. A Salon's Life: Field-Configuring Event, Power and Contestation in a Creative Field. In B. Moeran and J. S.

Pedersen (eds.), Negotiating Values in the Creative Industries. Cambridge: Cambridge University Press.

Elias, N. 2006. Court Society. Dublin: University College Dublin Press.

Haug, W. 1986. Critique of Commodity Aesthetics: Appearance, Sexuality, and Advertising in Capitalist Society. University of Minnesota Press.

Havens, T. 2011. Inventing Universal Television: Restricted Access, Promotional Extravagance, and the Distribution of Value at Global Television Markets. In B. Moeran and J. S. Pedersen (eds.), Negotiating Values in the Creative Industries. Cambridge: Cambridge University Press.

Karpik, L. 2010. Valuing the Unique: The Economics of Singularities. Princeton: Princeton University Press.

Knox, H., O’Doherty, D.,Vurdubakis C. Westrup 2007. Transformative Capacity, Information Technology, and the Making of Business Experts. The Sociological Review, 55:1: 22-41.

Levi-Strauss, Claude. Chicago: University of Chicago Press. The Savage Mind. 1968.

McKenna, C. 2006. The World's Newest Profession. Cambridge: Cambridge University Press.

Malefyt, T. 2003. Models, Metaphors and Client Relations: The Negotiated Meanings of Advertising . In T. Malefyt and B. Moeran (eds.), Advertising Cultures. Oxford: Berg.

Malinowski, B. 1984. Argonauts of the Western Pacific. New York. Waveland Press.

Mason, A. 2012 (with M Stoilkova). Corporeality of Consultant Expertise. Northern Studies 6, 2: 85-98.

Mason, A. 2007. Consultant Forecasting in Liberalized Gas Markets. Public Culture 19, 2: 367-379.

Mason, A. 2006. Images of the Energy Future. Environmental Research Letters 1, 1: 12-20. 
Menand L. 2010. Top of the Pops. The New Yorker, 11 January 2010.

Moeran, B. 2010. The Book Fair as a Tournament of Values. Journal of the Royal Anthropological Institute 16, 138-154.

Moeran, B. 2005. Tricks of the Trade: The Performance and Interpretation of Authenticity. Journal of Management Studies 42, 5: 901-922.

Moeran, B. and J. S. Pedersen, 2011. Introduction. In B. Moeran and J. S. Pedersen (eds.), Negotiating Values in the Creative Industries. Cambridge: Cambridge University Press.

Munn, N. 1986. Fame of Gawa. Duke University Press.

Petric, V. 1999. Commentary to Andrei Rublev. Criterion Film Collection.

Shapin, S. 1994. A Social History of Truth. Chicago: University of Chicago Press.

Silverstein, M. 2006. Old Wine, New Ethnographic Lexicography. Annual Review of Anthropology 35:481-96.

Wallace, D. 2010. Governing the Future. Aukland: Commons Publishing. Wapner P. 1995. Politics Beyond the State. World Politics, 47, 3: 311-340.

Weber, M. 1946. From Max Weber. Gerth H. H. \& Mills C. W. (eds.). New York: Oxford University Press.

Wernick, A. 1994. Promotional Culture. London: Sage Publications.

Wilson, J. 1971. The Dead Hand of Regulation. The Public Interest, 25: 5478.

Žižek, S. 1991. The Sublime Object of Ideology. London: Verso.

Arthur Mason is visiting faculty at Rice University in the Department of Anthropology. He is an Arctic anthropologist specializing in cultures of expertise, oil and gas development, and ritual and performativity. Arthur was previously a Ciriacy-Wantrup Fellow in the Department of Geography at the University of California Berkeley, and is the co-editor of Subterranean Estates: Lifeworlds of Oil and Gas (Cornell University Press, 2015). A three-time Fulbright chair award grantee (Norway, Canada, Russia), he has a PhD in anthropology from UC Berkeley. Arthur may be reached at arthur.mason@rice.edu 